\title{
Formação Continuada de professores: os desafios da construção de propostas político-pedagógicas
}

\author{
Leny Cristina Soares Souza Azevedo \\ Universidade Estadual do Norte Fluminense \\ Maria Nailde Martins Ramalho \\ Universidade Federal dos Vales do Jequitinhonha e Mucuri
}

\section{Resumo}

Este texto apresenta os estudos que delinearam a pesquisa realizada nos anos de 2008 e 2009 na Universidade Estadual do Norte Fluminense, tendo como foco a proposta de formação continuada de professores implementada pela Secretaria Municipal da Educação em Campos dos Goytacazes - RJ. 0 objetivo da pesquisa foi analisar as implicações políticas e as práticas pedagógicas que permeiam o projeto de formação continuada de professores(as) para o Ensino Fundamental oferecido pela Equipe de Atualização Continuada (EAC/SEMC/RJ). Desse modo, a pesquisa encontra-se ancorada nas discussões feitas por Ferreira (2003), Roldão (1998), Gatti (2008) e outras(os). Esse processo de formação permanente é uma das dimensões relevantes para a materialização de uma política de valorização docente, e aponta para o reconhecimento da urgente necessidade de mudanças na forma de olhar a escola e o trabalho pedagógico.

Palavras-chave: Formação continuada. Prática pedagógica. Políticas educacionais. 


\section{Continuing Education of Teachers: the challenge of constructing political-pedagogical proposals}

This text presents the studies that have outlined the research conducted at Universidade Estadual do Norte Fluminense, from 2008 to 2009, focusing on a proposal for continuing education of teachers implemented by the Municipal Secretary of Education in the town of Campos dos Goytacazes - RJ. The research objective was to analyze the political implications and pedagogical practices that permeate the project for continued education of elementary school teachers offered by the Equipe de Atualização Continuada (EAC/SEMC/RJ). Thus, the research is anchored on discussions performed by Ferreira (2003), Roldão(1998), Gatti (2008) and others. This process of continuing education is one of the dimensions relevant for the materializing of a policy that values teaching professionals, and points to the recognition of an urgent need for changes in the way of looking at schools and pedagogical work.

Keywords: Continued education. Pedagogical practice. Educational policies.

\section{Formación continuada de profesores: los desafíos de la construcción de propuestas político-pedagógicas}

Este texto presenta los estudios que delinearon la investigación realizada en 2008 y 2009 en la Universidade Estadual do Norte Fluminense, teniendo por foco la propuesta de formación continuada de profesores(as) implementada por la Secretaría Municipal de Educación en Campos dos Goytacazes. El objetivo de la investigación fue analizar las implicaciones políticas y las prácticas pedagógicas que atraviesan el proyecto de formación continuada de profesores(asl para la Enseñanza Fundamental ofrecido por el Equipo de Actualización Continuada (EAC/SEMC/RJ). De este modo, la investigación se encuentra anclada en las discusiones hechas por Ferreira (2003), Roldão (1998), Gatti (2008) entre otras(os). Ese proceso de formación permanente es una de las dimensiones relevantes a la materialización de una política de valorización de los docentes, y apunta a lo reconocimiento de la urgente necesidad de cambios en la forma de ver la escuela y el trabajo pedagógico.

Palabras clave: Formación continuada. Práctica pedagógica. Políticas educacionales. 


\section{Introdução}

Na discussão das competências necessárias ao exercício da profissão de professor ou professora, Bittencourt (2003) analisa que, no espaço universitário, a formação continuada é entendida como uma das funções das universidades, em cooperação com as Secretarias estaduais e municipais de ensino ou com as escolas públicas. Comumente, são as parcerias entre as Secretarias de Educação e Universidades que programam cursos, oficinas, seminários, projetos de ensino e pesquisa para professores, e estes acolhem as propostas, todos "imbuídos das intenções de salvar, melhorar e aperfeiçoar a educação de crianças e jovens." (Bittencourt, 2003, p. 67)

Os desdobramentos dessa discussão e as práticas implementadas pelos poderes públicos e até mesmo pelas universidades conceituadas, secretarias estaduais e municipais de ensino, ainda estão por se estudar. 0 presente texto buscará pôr em sintonia os estudos sobre as políticas para a formação de professores e as especificidades da formação continuada. Sobretudo, estaremos considerando as pesquisas que cuidam das análises dos saberes docentes e seus significados, realçando a existência de um saber que é produzido pelos próprios professores, em contato com os cursos, no exercício da sala de aula, na interação com seus alunos e alunas.

0 projeto que desenvolvemos na UENF Darcy Ribeiro (2008 - 2009) possibilitou examinar os cursos ofertados pela Secretaria Municipal de Campos dos Goytacazes, na gestão da Secretária Auxiliadora Freitas (2004 - 2008), e o projeto “Viajando pelos campos, conhecendo nossas raízes", coordenado pela professora Marluce Guimarães Silva, destinado aos professores das primeiras séries do Ensino Fundamental da rede pública municipal.

Selecionamos três escolas municipais localizadas na universidade com a finalidade de acompanhar mais regularmente o investimento dos docentes na Formação Continuada. Entrevistamos 18 professores e professoras e recolhemos depoimentos a respeito dos entraves e possibilidades dos cursos para a melhoria do trabalho educativo nas séries iniciais.

Com essa pesquisa, questionamos os significados da formação continuada e suas contribuições para as práticas pedagógicas, partindo do princípio de que essa modalidade de formação vem se destacando nas discussões das políticas educacionais no Brasil desde a sanção da atual Lei de Diretrizes e Bases da Educação - LDB, em meados da década de 1990 (Brasil, 1996), apontando para uma revisão das experiências, dos percursos formativos e profissionais no âmbito nacional.

0 Ponto de partida desse trabalho foi a aproximação à Equipe de Atualização Continuada - EAC em Campos dos Goytacazes, responsável pelo programa de Formação Continuada para docentes das primeiras séries do ensino fundamental. Esse contato 
permitiu a investigação da história da proposta pedagógica do projeto oferecido aos docentes da rede pública municipal, através da consulta de documentos e entrevistas feitas com a coordenadora. Posteriormente a esse levantamento de dados, propusemonos à análise das propostas de formação para a melhoria das estratégias de ensino desenvolvidas pelos professores e professoras.

\section{Formação continuada no centro das reformas educacionais}

A formação continuada é uma das dimensões importantes para a materialização de uma política para os profissionais da educação, e acreditamos que deve estar articulada à formação inicial e às boas condições de trabalho, salário e carreira. Essa articulação faz-se necessária em razão dos novos contornos na organização escolar. São diretrizes que tendem a alterar a divisão do trabalho na escola, a eliminar algumas rotinas e a estabelecer outras, a extinguir ou substituir hierarquias, a demandar por novos procedimentos profissionais. Hoje, pressupõe-se que o professor ou professora deva atuar na escola para promover o trabalho coletivo de elaboração de planejamento escolar, dos programas e currículos. Tudo isso, de acordo com Ferreira (2003), requer formação e condições para se sustentar um projeto democrático.

As mudanças trazidas na referida legislação de ensino (LDB 9.394/96), quanto à participação dos docentes na gestão e construção de projetos na escola, repercutiram na organização do trabalho escolar, pois exigiram, de acordo com Oliveira (2007), mais tempo de trabalho ou mais demandas durante a jornada de trabalho. Essas demandas se traduzem em mais tempo, tanto de maneira extensiva como intensiva, e acabam resultando em intensificação do trabalho, quando não provocando, diretamente, aumento na sua jornada.

0 incentivo à formação continuada privilegia a focalização na responsabilidade dos professores de forma que possam construir estratégias de ensino, visando interagir produtivamente com os discentes. Aponta, também, a necessidade de serem profissionais capazes de ultrapassar os conhecimentos do senso comum, sem desconsiderá-lo, além de ter habilidades de investigação para compreender o saber fazer derivado não só do curso de formação, mas também de sua matriz cultural.

Essa é, sem dúvida, uma contradição a ser explorada quando a intenção é sair do discurso, visando à transformação. A falta de um olhar para dentro das escolas, de acordo com Nunes (2007), vem, ao longo dos tempos, contribuindo para a manutenção das desigualdades sociais, não podendo os conflitos e contradições presentes ser ignorados. 
A necessidade desse olhar é apontada pelos indicadores educacionais, observandose que os resultados das avaliações têm focalizado a precariedade da formação de professores e a desvalorização da profissão. Esses indicadores revelam, através do Sistema de Avaliação da Educação Básica (SAEB), da Prova Brasil e de outras avaliações estaduais e municipais, o desempenho insatisfatório de estudantes, principalmente em leitura e escrita nas séries iniciais do ensino. Aumentam, assim, as expectativas em relação às interpretações dos artigos 62 e 64 da LDB 9.394/96, referentes à formação, exigindo a ampliação do tempo destinado à dimensão formativa docente.

O Brasil adotou essa posição, mas somaram-se outros significados à proposta de Formação Continuada para tentar solucionar os problemas gerados pela precária formação inicial dos docentes. Como aponta Gatti:

[...] concretamente ampliou-se o entendimento sobre educação continuada, com esta abrangendo muitas iniciativas que, na verdade, são de suprimento a uma formação precária pré-serviço e nem são sempre propriamente de aprofundamento ou ampliação de conhecimentos. Isso responde a uma situação particular nossa, pela precariedade em que se encontram os cursos de formação de professores em nível de graduação. (Gatti, 2008, p. 58)

Ainda em Gatti (2008), entendemos que as propostas de Formação Continuada implementadas pelas secretarias estaduais e municipais de educação assumiram feições de compensação para sanar os problemas gerados pelas deficiências da formação docente inicial, não cumprindo o que os debates internacionais haviam definido quanto à necessidade de uma base sólida, e posterior amadurecimento intelectual com os cursos de educação continuada.

Nesse mesmo percurso, podem ser destacadas as ofertas de cursos de Educação Continuada para professores das séries iniciais do ensino, oferecidos pela Secretaria Municipal de Educação em Campos dos Goytacazes. Essa afirmação foi constatada nos depoimentos, nos quais os entrevistados revelaram que buscam os cursos para receber conhecimentos que não tiveram na formação inicial e que as razões da busca são a vontade de aprimorar os saberes e a prática. Os discursos revelam, assim, que os docentes percebem-se muito carentes de certos conteúdos, e por isso procuram a formação continuada. Os registros, tanto de uma professora da Escola Municipal Francisco de Assis, quanto de um professor da Escola Municipal Maria Arlete Araújo, são bastante expressivos:

0 que me levou a participar dos cursos de Formação continuada foi porque eu acho que o ser humano em si em qualquer profissão que ele esteja empenhando suas atividades, o profissional ele tem que melhorar, ele tem que ter isso em mente e procurar sempre 
algo a mais. E a vida está cheia de coisas diferentes e a gente tem que estar sempre se aperfeiçoando, estando aberta a mudanças. (Professora, Escola Municipal Francisco de Assis)

0 projeto de formação continuada sobre o Patrimônio Cultural me interessa muito no que diz respeito a história de Campos, porque nós professores somos muito carentes em saber do próprio município. Então como eu vou falar para meus alunos de Campos dos Goytacazes se eu não conheço a história da cidade? (Professor, Escola Municipal Maria Arlete Araújol

Para os entrevistados, o processo cumpre sua função, mas essas lacunas na formação deveriam ser preenchidas pelas universidades públicas, caso as políticas educacionais investissem mais recursos na formação docente inicial. Assim, a formação inicial seria de qualidade, e a educação Continuada poderia aprimorar e trazer avanços para os profissionais da educação - consequentemente, para o processo ensino-aprendizagem dos alunos e alunas.

É claro que não somente a formação inicial e a continuada poderão impulsionar a qualidade educacional. Salários melhores, planos de carreira, escolas bem equipadas, parcerias entre escola e comunidade são algumas das possibilidades de investimento na ampliação dos diferentes campos da atuação educativa. A LDB nº 9.394/96 define a formação nos artigos referentes à valorização profissional. Primeiramente, o artigo 40 dispõe que “A educação profissional será desenvolvida em articulação com o ensino regular ou por diferentes estratégias de educação continuada, em instituições especializadas ou no ambiente de trabalho." (Brasil,1996)

0 artigo 67 estipula que os sistemas de ensino promoverão a valorização dos profissionais da educação, inclusive nos termos dos estatutos e dos planos de carreira do magistério público. E também, em seu inciso II, que “o aperfeiçoamento profissional continuado, inclusive com licenciamento periódico remunerado para esse fim, é deferido." (Brasil, 1996) Em seu artigo 80, prevê que "0 Poder Público incentivará o desenvolvimento e a veiculação de programas de ensino à distância, em todos os níveis e modalidades de ensino, e de educação continuada." (Brasil, 1996)

Por fim, o artigo 87, $\S 3^{\circ}$, inciso III, define que cada município e, supletivamente, o Estado e a União, deverá realizar programas de capacitação para todos(as) os(as) professores(as) em exercício, utilizando também, para isso, os recursos da educação à distância (Brasil, 1996).

Refletindo sobre o que a lei dispõe, alguns aspectos não se comprovam na realidade dos profissionais entrevistados na pesquisa. Nos depoimentos, constatamos que as escolas não oferecem nenhum espaço, nem tempo, de formação continuada. Elas deixam apenas a Secretaria Municipal de Educação de Campos - SMEC responsável por 
oferecer cursos de formação. Mas acreditamos que, se elas trabalhassem em conjunto com as propostas da SMEC, proporcionariam maior envolvimento da equipe docente, e também aproveitamento educacional.

Com base nesse contexto vivenciado pela Equipe de Formação Continuada - EAC, percebemos que as escolas em questão devem atentar para suas responsabilidades e agir de forma a auxiliar os docentes a realizarem seu processo de formação. Fazendo isso, elas estarão, como dispõe a Lei, valorizando seus profissionais. É claro que existem inúmeras formas de valorização, mas a formação deve ser pensada como primordial para a melhoria da qualidade da educação.

Os depoimentos também revelam que o horário dos cursos é outro fator limitante para a formação continuada. A maioria dos cursos é ministrada no mesmo período em que os professores estão lecionando, e as escolas não podem liberá-los porque não estão preparadas para substituí-los nesses momentos de ausência. Por seu lado, a secretaria de educação também não planeja os cursos, que deveriam ser realizados em momentos em que os docentes pudessem participar sem prejuízo das atividades docentes.

Assim, observamos que as mudanças introduzidas com a legislação de ensino e os estímulos à preparação docente ainda não efetivaram os caminhos da melhoria da qualidade educacional. Para Roldão (1998), esse percurso para a qualidade deve levar em conta que o ponto de partida é a assunção da necessidade de um reforço da qualidade e de promoção da excelência no que se refere aos professores e professoras, e muito particularmente às que trabalham nas séries iniciais de ensino.

\section{Formação continuada e a proposta político-pedagógica em Campos dos Goytacazes}

Em 2008, através do Projeto de Iniciação Científica - UENF/CNPq, consultamos os documentos que subsidiavam os programas para a Formação Continuada realizados pela Secretaria Municipal de Educação de Campos dos Goytacazes - SMEC. Tivemos acesso aos Documentos da Gerência Pedagógica acerca da proposta educativa para docentes das séries iniciais do ensino: com duração de oito meses e totalizando 160 horas, a proposta seria ministrada pela EAC e coordenada pela professora de história Marluce Guimarães Silva. Foram oferecidas palestras e oficinas no Colégio 29 de maio, nas quais a equipe ministrou reflexões sobre a interdisciplinaridade e um tema foi escolhido, colocando-se as áreas do conhecimento a serviço dele. Segundo a professora Carmem Braga, integrante da equipe: 
A partir do tema Campos-Formosa trabalhamos: português, matemática, geografia, diversidade cultural e história. Lá, no 29 de maio, nos distribuímos em oficinas que discutiam o rio Paraíba, espaço, fronteiras, limites de Campos, quais são os distritos, na parte de geografia; Marluce, com a história de Campos; outro professor falava de distância (matemática), meio ambiente, mostrando os impactos ambientais que nós estamos vendo aí, com o derramamento de resíduos químicos e industriais no rio. Campos como Centro, e os outros conhecimentos formatados em torno dessa temática. (Entrevista concedida em maio de 2008)

Com relação às inscrições nos cursos, a Secretaria de Educação realizou reuniões com diretores e diretoras, nas quais foi divulgada toda a programação de cursos. Os temas dos cursos foram planejados pela EAC - por exemplo, no curso "Viajando pelos campos, conhecendo nossas raízes", que aconteceu em forma de "tour", a história de Campos é narrada e subsidiada com os referenciais do Patrimônio Histórico-Cultural.

Essa proposta desenvolveu-se a partir de um estudo sobre a história do município de Campos e da visita a alguns prédios, praças, pontos turísticos que pertencem ao Patrimônio Histórico e Cultural do município. 0 avanço da educação patrimonial tem sido, segundo Teixeira (2008), um importante recurso à cidadania, sendo uma prática social educativa que propicia aos indivíduos reconhecerem-se nas mais diferentes manifestações culturais de sua comunidade (Teixeira, 2008). De acordo com o documento “Por uma Educação íntegra”, de 2008, o projeto é importante porque

É uma atividade significativa para professores e alunos, uma vez que propicia a valorização da história e da cultura local, importante para a construção de cidadãos atuantes. Embora, muitas vezes, a visita a um prédio de valor histórico possa ser confundida com uma simples excursão, na verdade inclui outras atividades, como por exemplo, observação, pesquisa, entrevista, trabalho com mapas, roteiros, leitura de textos, constituem um experiência rica para o professor e para o aluno. (SMEC, 2008, p. 1)

A partir de outubro de 2009, esse projeto foi alterado pela nova gestão municipal, pois temas de propostas para a Prova Brasil foram introduzidos na tentativa de melhorar o resultado de avaliações anteriores, em que o resultado do município foi precário. 0 conceito de qualidade, segundo Roldão (1998), relaciona-se, entre outros, com uma preocupação com os desempenhos profissionais. Nos dias de hoje, isso é particularmente relevante no campo educacional, em parte por razões econômicas, é certo, mas também pela defesa do papel insubstituível de uma escola pública para todos, nas sociedades atuais (Roldão, 1998, p. 21).

No que concerne aos padrões de gestão pública, é importante registrar as análises feitas por Cunha (1998) quanto às diferentes razões que fazem com que um(a) secretário(a) 
de Educação "tenha o seu plano de carreira, a sua proposta curricular, o seu tipo de arquitetura escolar, as suas prioridades" (Cunha, 1998, p. 18). Assim, os planos de carreira, as propostas curriculares e as prioridades mudam a cada quatro anos. Muitas vezes, conforme esse autor, até em menos tempo, já que nem todos permanecem à frente da Secretaria durante todo o mandato de um(a) prefeitolal ou governador(a). Isso pode ser observado nas gestões conflituosas e contraditórias de Campos dos Goytacazes.

Por outro lado, a descontinuidade desses padrões de administração gera a desconfiança de professores com relação a desenvolverem mudanças, pois a cada início de gestão recebem pacotes de estratégias e planos. Os docentes acabam desenvolvendo resistências diante de projetos, pois muitas vezes sabem que não vão durar (Cunha, 1999).

Assim, ao voltarmos nossos olhares para a formação continuada em Campos dos Goytacazes, torna-se imprescindível atentarmos para os cursos ofertados, assim como considerar as dificuldades enfrentadas por coordenadores, professores e, principalmente, avaliar suas contribuições para a formação continuada.

A prefeitura investiu nesse projeto no biênio 2008 - 2009 pela contratação de professores e professoras de diversas áreas, para dar cursos aos profissionais da rede pública de ensino municipal com o objetivo de atualizar os docentes em suas práticas pedagógicas. Foram introduzidos, inicialmente, os cursos de alfabetização, que destacavam a história de Campos dos Goytacazes e seu entorno. Algum tempo depois, os cursos foram suspensos, mas como houve um grande interesse pela história de Campos, foram reformulados e passaram a atender crianças do $4^{\circ}$ ano das escolas públicas, que estavam estudando a história de Campos. Essas descontinuidades são frequentes e detectamos, nas entrevistas, as dificuldades quanto à disponibilização de recursos para dar sustentação às atividades de formação.

A participação dos professores, de acordo com os documentos consultados (SMEC Avaliação 2008), tem sido regular. Os docentes não são obrigados a fazer o curso. Algumas vêm por vontade própria; outros vêm pensando no aumento salarial de $3 \%$ que ganham ao completar 40 horas de atividades pedagógicas fora da sala de aula; e muitos vêm porque também querem uma atualização do trabalho pedagógico. Apesar da avaliação positiva, a maioria das entrevistadas questionou o fato dos cursos serem ofertados em horários durante a semana, o que compromete o andamento das aulas nas escolas ou determina a falta de professores aos cursos:

Os cursos de formação continuada possibilitam reflexão sobre a prática, porque às vezes a gente fica muito bitolado ao método tradicional. 0 corre-corre do dia-a-dia faz com que a gente não tenha criatividade, e os cursos de Formação Continuada oferecem a oportunidade de tornarmos as aulas mais dinâmicas e o tratamento dos conteúdos motivam mais os alunos a aprenderem. (Professora, entrevista concedida em 2009) 
Para Alencar (2007), a criatividade deve ser levada em conta porque o seu cultivo e desenvolvimento apontam para

[...] o reconhecimento de que a necessidade de criar é uma parte saudável do ser humano, sendo a atividade criativa acompanhada de sentimentos de satisfação e prazer, elementos fundamentais para o bem-estar emocional e saúde mental. Uma segunda razão diz respeito ao cenário atual, caracterizado por incerteza, complexidade, progresso e mudanças que vêm ocorrendo em um ritmo exponencial, gerando desafios e problemas imprevisíveis, que requerem soluções criativas. Uma terceira é que sufocar o desenvolvimento do potencial criador equivale a limitar as possibilidades de uma realização plena e a expressão de talentos diversos. (Alencar, 2007, p. 45)

Por fim podemos destacar que, apesar dos entrevistados tentarem incorporar práticas criativas em sala de aula, visando despertar a criatividade de alunas e alunos, ainda encontram muitas dificuldades em romper com suas práticas tradicionais.

As dificuldades mais pontuais por parte dos professores e das professoras, e também da equipe, são a falta de bibliografia para estudo e utilização nas aulas. As que existem em Campos não são mais editadas ou não são encontradas. Segundo Figueiredo (2002),

A discussão acerca da educação patrimonial é bastante recente no Brasil, como a temática do Patrimônio histórico de forma geral. Foi introduzida no país em torno dos anos 80 do século $X X$, baseando-se nas atividades educacionais já em andamento nos espaços culturais europeus. Hoje, já encontramos disponíveis algumas cartilhas de atividade sobre educação patrimonial, mas o tema ainda é bastante incipiente para a maior parte dos professores que atuam no ensino médio. (Figueiredo, 2002, p. 57)

Os caminhos trilhados pela EAC e os trabalhos desenvolvidos com os docentes contribuíram para momentos de trocas de experiências, estimulando o conhecimento sobre o patrimônio cultural e suas histórias, e também socializando informações e repensando práticas profissionais. Há uma histórica desvalorização do trabalho docente, com atribuição de baixos salários e instabilidade profissional. Isso ocorre, principalmente, porque esses profissionais, em sua maioria, são contratados, e não concursados para ingressar na carreira. Em sua carga horária não há previsão de atividades pedagógicas. Além disso, na escola existe uma precariedade de materiais didáticos, equipamentos e espaço físico. Agrava-se a situação com a falta de formação contínua promovida a partir das necessidades de trabalho docente, que vá ao encontro dos âmbitos pedagógicos do ensino. 


\section{Conclusão}

Para Carrolo (1997), outros fatores ainda deterioram a profissão, como a progressiva incompreensão e ausência de reconhecimento social da função docente, a indefinição institucional da escola e a proliferação de papéis exigidos do professor e da professora. Esses fatores intensificam o afastamento social e cultural do professorado, apontando para questionamentos dos processos de formação docente, o que significa interrogar e desfiar a trama de acontecimentos e práticas escolares que integram as relações entre a escola, as reformas educacionais e os projetos político-pedagógicos.

Para tanto, é interessante observarmos as progressivas gerações de professoras e professores que, segundo Collares (1999), têm sido chamados a "qualificar-se", e razões não faltam para ser proclamada essa necessidade: seja por causa de uma nova legislação de ensino, seja pela precariedade da formação inicial docente, seja pela urgência de "atualização" que permita o acompanhamento das mudanças vertiginosas no campo do conhecimento, entre outras razões (Collares, 1999, p. 203).

Neste cenário de expectativas constantes sendo colocadas é que surgem cada vez mais propostas e projetos por todo o Brasil, buscando reforçar a reclamada qualidade da formação para alcançar, segundo Roldão (1998), outra qualidade - a do desempenho profissional. A Formação Continuada se insere no grupo dessas iniciativas, e entendemos que é relevante indagar sobre seus significados, limites e possibilidades na materialização de condições estruturais que resultem em lógicas, rotinas e planos mais democráticos dentro das ações cotidianas das escolas, transformando-as em locais de formação permanente, capazes de sustentar um projeto mais justo de educação e sociedade.

\section{Referências}

ALENCAR, Eunice Maria Lima Soriano. Criatividade no contexto educacional: três décadas de pesquisa. Universidade Católica de Brasília. v. 23, 2007. Disponível em <http://www.scielo.br/pdf/ptp/v23nspe/07.pdf>. Acesso em: 22 set. 2009.

BRASIL. Lei de Diretrizes e Bases da Educação Nacional n. 9394/96. Disponível em <http://www.planalto.gov.br/CCIVIL_03/LEIS/L9.394.html>. Acesso em: 27 jul. 2009

CARROLO, Carlos. Formação e identidade profissional dos professores. In: ESTRELA, Maria Teresa (Org.). Viver e contruir a profissão docente. Porto: Porto, 1997. p. 24-26.

COLLARES,Cecília Azevedo Lima. Educação continuada e política da descontinuidade. Revista Educação e Sociedade: CEDES, n.68, p. 203-219, 1999.

CUNHA, Luiz Antonio. Seminário sobre indicador municipal de desenvolvimento educacional. Campinas: NEPO/UNICAMP, 1999. 
Política educacional: Impasses e alternativas. São Paulo: Cortez,1998.

FERREIRA, Naura Syria Carapeto (Org.). Formação Continuada e Gestão da educação. São Paulo: Cortez, 2003.

FIGUEIREDO, Betânia Gonçalves. Patrimônio Histórico e Cultural: um novo campo de ação para os professores. In: Grupo Gestor de Projeto de Educação Patrimonial. Reflexões e contribuições para a Educação Patrimonial. Belo Horizonte: SEE/MG, 2002. p.57-63.

GATTI, Bernardete Angelina. Análise das políticas públicas para formação continuada no Brasil, na última década. Fundação Carlos Chagas, 2008. Disponível em: $h t t p: / / w w w . s c i e l o . b r / p d f / r b e d u / v 13 n 37 / 06 . p d f$. Acesso em: 18 ago. 2009.

NUNES, Clarice. Formação docente: permanência do passado nos desafios do presente. In: Formação de professores para a educação básica: dez anos da LDB. SOUZA, João Valdir (Org). Belo Horizonte: Autêntica, 2007. p.127-129.

OLIVEIRA, Dalila, A educação básica na Lei de Diretrizes e Bases da Educação Nacional: breve balanço sobre a organização e o trabalho docente. In: SOUZA, João Valdir (Org.). Formação de professores para educação básica: dez anos de da LDB. Belo Horizonte: Autêntica, 2007. p.108-111.

ROLDÃO, Maria do Céu. Formar para a excelência profissional - pressupostos e rupturas nos níveis iniciais da docência. Programa de Pos graduação: Universidade Metodista de São Paulo. Educação e Linguagem, São Bernardo do Campo, v 1, n.1, p.18-42, 1998.

TEIXEIRA, Simone. Arquitetura Eclética em Campos dos Goytacazes. In: TEIXEIRA, Simone. Contribuições à prática pedagógica para a educação patrimonial . Campos dos Goytacazes: EDUENF, 2008. p.5-6.

Recebido em março de 2010

Aprovado em agosto de 2010

Leny Cristina Soares Souza Azevedo possui doutorado em Educação pela Universidade Estadual de professora adjunta da Universidade Federal do Rio de Janeiro - UFRJ. Tem experiência na área de Educação, com ênfase em Formação de Professores e Políticas Educacionais para o Ensino Médio. E-mail: leny.azQhotmail.com.

Maria Nailde Martins Ramalho, doutora em Educação pela Universidade Metodista de Piracicaba, é professora, pesquisadora e vice-diretora do Instituto de Humanidades da Universidade Federal dos Vales do Jequitinhonha e Mucuri - UFVJM. E-mail: nailderamalhodgmail.com. 